\title{
Influence of Copper(I) on Europium-containing Micelles
}

\author{
Zhao-Ye LI ${ }^{1, a^{*}}$, Zhao-Jun XUE ${ }^{2, b}$, Li-Jun KONG ${ }^{3, c}$ \\ 1,2Tianjin University of Technology and Education, Tianjin, China, 300222 \\ ${ }^{3}$ Tianjin Port Free Trade Zone Konggang School, 300300 \\ azhaoyeqingdao@163.com, ${ }^{b}$ zjxue_pd@tju.edu.cn, ${ }^{9}$ ljkong2013@163.com \\ ${ }^{*}$ Corresponding author
}

Keywords: Copper Luminescence Micelles.

\begin{abstract}
This paper explains and demonstrates influence of copper (I) on europium (Eu)-containing micelles. Main influence contains hindering formation of Eu-containing micelles and quenching luminescence. That is because of coordination of copper (I) with 4-vinyl pyridine (4VP). Competition occurred in coordination between $\mathrm{Cu}(\mathrm{I})$ and $\mathrm{Eu}(\mathrm{III})$.
\end{abstract}

\section{Introduction}

Recently, rare earth ions have been studied heavily. That is because of their special photo physical properties, such as high color purity, long afterglow time and high quantum yield [1], and so on. These special properties can be used in kinds of applications, for example, anti-counterfeiting, glow lamp and some high end weapons. Though these photo physical properties origin from rare earth ions, inorganic ions can emit only weak photoluminescence. It is because these inorganic ions have low ultraviolet light absorption coefficient. In order to emit higher photo luminescence, these inorganic ions usually coordinate with organic ligands or polymers. These ligands usually have high absorption coefficient for п-пconjugation effect. That is named "antenna effect" [2].

In most cases, coordinated inorganic matter can only dissolve in some special solvent with high polarity (such as dimethylsulfoxide). This resists applications of coordinated inorganic matter heavily. Compared with organic ligands, polymers have more advances, such as wide source, low cost and good flexibility. What is more is that some coordinated polymers also have high absorption coefficient. However, coordinated mono-polymers and homopolymers still don't dissolve in common solvents, such as ethyl alcohol, acetone, and so on. To resolve the problem, block copolymers are incorporated into coordination [3]. These block copolymers have two blocks with different polarity. One can disperse easily in routine solvent, and the other collapse in the same solvent. That is named core-shell micelles [4].

Block copolymers are synthesized by atom transfer radical polymerization (ATRP) with $\mathrm{CuCl}$ as catalyst. In the process of ATRP, cuprous ion can coordinate with dipyridy [5], just as rare earth ions located in the same transition period. In the formation of micelles induced by rare earth ions, residual cuprous ion can compete with coordinated central rare earth ions. Then residual cuprous ion can influence formation of micelles and luminescence of central rare earth ions.

In this paper, poly (ethylene glycol)-block-poly(4-vinylpyridine) (PEG-b-P4VP) is polymerized by ATRP. Influence of cuprous ions is discussed carefully in the following, especially in formation of micelles and luminescence.

\section{Experiments}

\section{Materials}

$\mathrm{EuCl}_{3} \cdot 6 \mathrm{H}_{2} \mathrm{O}$ was prepared by adding $\mathrm{Eu}_{2} \mathrm{O}_{3}(99.99 \%)$ powder into concentrated hydrochloric acid (36.5\%). Poly (ethylene glycol) mono methyl ether $\left(\mathrm{CH}_{3} \mathrm{O}-\mathrm{PEG}_{114}-\mathrm{OH}, \mathrm{Mw}=5,000\right.$ and poly dispersity index $=1.5$ ) was purchased from Fluka. 4-vinylpyridine (95\%) was purchased from Acros Organics. 


\section{Synthesis of PEG114-b-P4VP59}

The macro initiator $\mathrm{PEG}_{114}-\mathrm{Br}$ was synthesized according to [6]. The composition of the macro initiator PEG114-Br was characterized by the ${ }^{1} \mathrm{HNMR}$ spectrum recorded $\mathrm{inCDCl}_{3}$. The block copolymer $\mathrm{PEG}_{114}$-b-P4VP 59 was synthesized by atom transfer radical polymerization [7]. The composition of the block copolymer was determined by using the 1HNMR spectrum recorded in $\mathrm{CDCl}_{3}$ with the PEG block as the inner standard. The poly dispersity index (Mw/Mn) of the block copolymer was determined to be 1.15 by gel permeation chromatography with $\mathrm{N}, \mathrm{N}$-dimethyl formamide as the eluent and narrowly distributed poly(methyl methacrylate) as the calibration standard.

\section{Preparation of the complex micelles}

Four milliliters of $\mathrm{EuCl}_{3}$ ethanol solution $\left(\mathrm{c}_{\mathrm{Eu}(\mathrm{III})}=2.7 \times 10^{-3} \mathrm{mmol} / \mathrm{ml}\right)$ was dropped into $10 \mathrm{ml}$ block copolymer ethanol solution $\left(\mathrm{c}_{4 \mathrm{VP}}=5.3 \times 10^{-3} \mathrm{mmol} / \mathrm{ml}\right)$ under continuous magnetic stirring. The calculated molar ratio of $\mathrm{n}_{4 \mathrm{VP}}: \mathrm{n}_{\mathrm{Eu}}$ is $5: 1$.

Four milliliters of $\mathrm{EuCl}_{3}$ ethanol solution $\left(\mathrm{c}_{\mathrm{Eu}(\mathrm{III})}=9 \times 10^{-4} \mathrm{mmol} / \mathrm{ml}\right)$ was dropped into $10 \mathrm{ml}$ block copolymer ethanol solution $\left(\mathrm{c}_{4 \mathrm{VP}}=1.77 \times 10^{-3} \mathrm{mmol} / \mathrm{ml}\right)$ under continuous magnetic stirring. The calculated molar ratio of $\mathrm{n}_{4 \mathrm{VP}}: \mathrm{n}_{\mathrm{Eu}}$ is $5: 1$.

\section{Equipment}

Dynamic light scattering (DLS) measurements were performed by using a laser light scattering spectrometer (BI-200SM) equipped with a digital correlator (BI-9000AT) at $25^{\circ} \mathrm{C}$. Filtering solutions (about $1 \mathrm{ml}$ ) through a $0.45 \mu \mathrm{m}$ Millipore filter into a clean scintillation vial was manipulated to obtain the samples. More detailed information on the DLS measurements could be found in [8]. Atomic force microscopy (AFM) measurements were performed on a Digital Instruments Nanoscope multimode atomic force microscope (Veeco Metrology Group) in tapping mode. IR data were collected on Bio-Rad FTS-6000 IR spectrometer in the range of 4,000-400 $\mathrm{cm}^{-1}$ using $\mathrm{KBr}$ pellets. Photoluminescence (PL) spectra were obtained using a fluorescence spectrophotometer (HITACHI F-4600) equipped with a photomultiplier tube, with a xenon lamp as the excitation source at room temperature. All PL spectra were measured in the same PMT voltage (900 voltage), and the same excitation and emission splits $(10 \mathrm{~nm})$.

\section{Results and Discussion}

When block copolymer was dissolved in ethanol, they can disperse well for the two soluble blocks (PEG and P4VP). However, residual $\mathrm{Cu}(\mathrm{I})$ in ATRP could coordinate with 4VP units. That resulted in small aggregation of block copolymers. Diameters of block copolymer were shown in Fig. 1a, which indicated coordination of $\mathrm{Cu}(\mathrm{I})$. When molar concentration of block copolymer was above critical micelle concentration, block copolymer could aggregate together. Diameters of Eu-containing micelles were shown in Fig. 1b, which indicated coordination between $\mathrm{Eu}(\mathrm{III})$ and $4 \mathrm{VP}$ units.
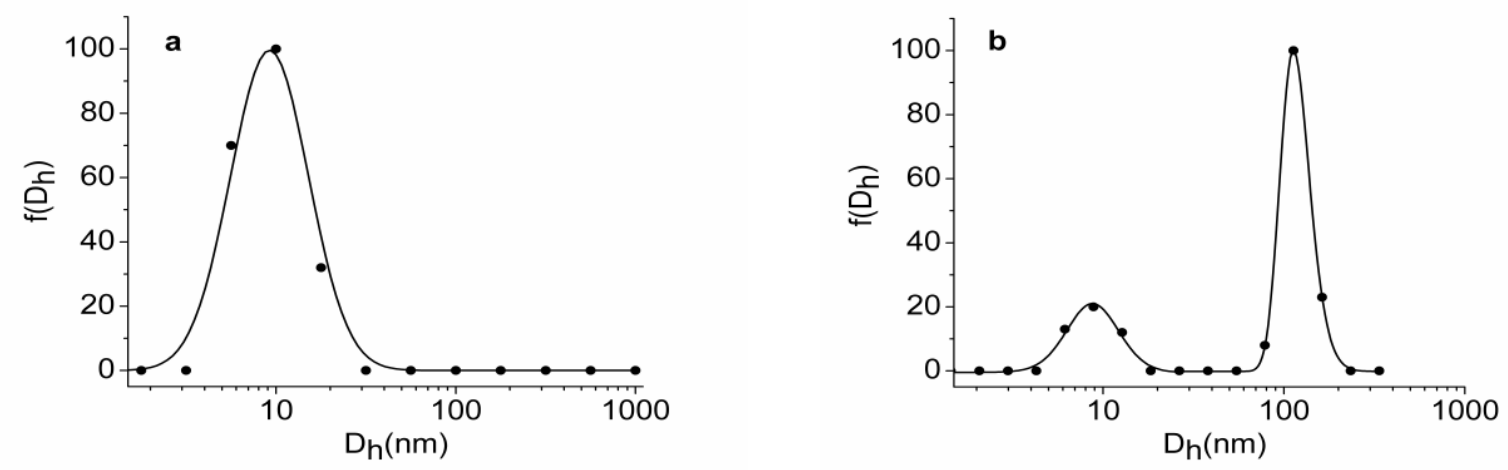

Fig.1 Results of DLS measurements: (a) block copolymer PEG-b-P4VP (b) Eu-containing micelles. 
Compared with Fig.1a and 1b, there was still a weak peak in about $10 \mathrm{~nm}$. That indicated residual $\mathrm{Cu}(\mathrm{I})$ ions participated in coordination, which resulted in different diameters of micelles.

Tab.1 Strength of special peaks in different situations

\begin{tabular}{|l|l|l|l|l|}
\hline \multicolumn{1}{|c|}{$\begin{array}{l}\text { Strength of } \\
\text { peak } \\
\mathrm{n}_{\mathrm{Eu}}: \mathrm{n}_{4 \mathrm{VP}}\end{array}$} & $592 \mathrm{~nm}$ & $616 \mathrm{~nm}$ & $652 \mathrm{~nm}$ & $701 \mathrm{~nm}$ \\
\hline $0: 5 \quad 40.5$ & 35.7 & 33.2 & 32.8 \\
\hline $\begin{array}{l}1: 5 \quad\left(\mathrm{c}_{4 \mathrm{VP}} \text { is above }\right. \\
\mathrm{cmc})\end{array}$ & 759.7 & 2404 & 135.3 & 355 \\
\hline $\begin{array}{l}1: 5 \quad\left(\mathrm{c}_{4 \mathrm{VP}} \text { is below }\right. \\
\mathrm{cmc})\end{array}$ & 540.7 & 590.2 & 510.8 & 530.6 \\
\hline $1: 0$ & 510.3 & 540.2 & 470.8 & 490.3 \\
\hline
\end{tabular}

When block copolymer solution was measured by PL, there were only scattered light, shown in Tab.1. Under excited ultraviolet light at $394 \mathrm{~nm}$, central Eu(III) ions could emit four special peaks at $592 \mathrm{~nm}, 616 \mathrm{~nm}, 652 \mathrm{~nm}$ and $701 \mathrm{~nm}$. These four different peaks are all caused by electron transitions from ${ }^{5} \mathrm{D}_{0} \rightarrow{ }^{7} \mathrm{~F}_{\mathrm{J}}(\mathrm{J}=1,2,3,4)$ [9]. When $4 \mathrm{VP}$ units coordinated with $\mathrm{Eu}$ (III) ions, strength of luminescence in different peaks both increased. In the high concentration of $\mathrm{c}_{4 \mathrm{VP}}$ (above $\mathrm{cmc}$ ), strength at $616 \mathrm{~nm}$ was about four times than that without polymers. However, Below cmc, strength at $616 \mathrm{~nm}$ was a little stronger than that only containing $\mathrm{Eu}(\mathrm{III})$ ions. One reason was caused by different concentrations of $\mathrm{Eu}(\mathrm{III})$ ions. The other reason may be that residual $\mathrm{Cu}(\mathrm{I})$ weakened luminescence of $\mathrm{Eu}$ (III) ions by coordination.

\section{Summary}

In this paper, influence of $\mathrm{Cu}(\mathrm{I})$ was discussed carefully. It was included influence of micelles formation and luminescence of $\mathrm{Eu}(\mathrm{III})$ ions. Below critical micelle concentration, residual $\mathrm{Cu}(\mathrm{I})$ competed with $\mathrm{Eu}$ (III). This not only influenced the formation of micelles, but only influenced the luminescence of central ions. When concentration of block copolymers was above critical micelle concentration, the weaken effect was not obvious.

\section{Acknowledgement}

This work was supported by the Tianjin University of Technology and Education Scientific Research Foundation (NO. KY14-70) and Tianjin Higher Education Development FundProjects (NO. 20100114).

\section{References}

[1]N L Puntus, A. Lyssenko K, S I Pekareva, J C G buhzli. Intermolecular interactions as actors in energy-transfer processes in lanthanide complexes with 2,2'-bipyridine. J. Phys. Chem. B, 113 (2009) 9265-9277.

[2] Yan Bing, Qiao Xiaofei. Rare-earth/inorganic/organic polymeric hybrid materials: molecular assembly, regular microstructure and photoluminescence. J. Phys. Chem. B, 111(2007) 12362-12374.

[3]Li Zhaoye, Ma Rujiang, An Yingli, Shi Linqi. Micellization and luminescence of PEG-b-P4VP/europium(III)/1,10-phenanthroline complex . Colloid Polym Sci, 288 (2010), 1041-1046.

[4]Li Zhaoye, Xue Zhaojun, Kong Lijun. The Luminescence of rare earth composite micelles in different polarity. Advanced Materials Research, 772 (2013) 309-312. 
[5]D. P. Curran,et al. Group transfer addition reactions of methyl (phenylseleno)malononitrile to alkenes. J. Am. Chem. Soc., 116 (1994) 4279-4288.

[6]Ma RJ, Wang BL, Liu XJ, Li Y, An YL, He ZP, Shi LQ. Pyranine-induced micellization of poly(ethylene glycol)-block-poly(4-vinylpyridine) and $\mathrm{pH}$-triggered release of pyranine from the complex micelles. Langmuir, 23 (2007) 7498-7504.

[7] Wu K, Shi LQ, Zhang WQ, An YL, Zhang X, Li ZY, Zhu XX. Thermoresponsiveness of hybrid micelles from poly(ethylene glycol)-block-poly(4-vinylpyridium) cations and $\mathrm{SO}_{4}{ }^{2-}$ anions in aqueous solutions. Langmuir, 22(2006) 1474-1477.

[8]Zhang WQ, Shi LQ, An YL, Gao LC, Wu K, Ma RJ, He BL. Initial copolymer concentration influence on self-assembly of PS38-b-P(AA190-co-MA20) in water. Phys Chem Chem Phys, 6(2004) 109-115.

[9]Qiao XF, Yan B. Assembly, characterization, and photoluminescence of hybrids containing europium(III) complexes covalently bonded to inorganic $\mathrm{Si}-\mathrm{O}$ networks/organic polymers by modified $\beta$-diketone. J Phys Chem B, 112 (2008) 14742-14750. 